\title{
Renal cell carcinoma with renocolic fistula presenting as an emphysematous pyelonephritis in a non-functioning kidney: case report
}

\author{
Manharsinh Rajput*, Phanindra Mohan Deka and Sharwan Kumar Singhania
}

\begin{abstract}
Background: The uniqueness of this case is in its rarity and divergent presentation.

Case presentation: Here, we report a case of 56-year-old male patient with pain in the left flank for 1 year. On evaluation, patient was diagnosed with multiple left renal calculi and emphysematous pyelonephritis with non-functioning kidney. Intraoperatively, dense perinephric adhesions, necrotic kidney and renocolic fistula were encountered. The patient underwent left nephrectomy with resection anastomosis of descending colon segment with loop ileostomy. Histopathological examination showed a poorly differentiated high-grade clear cell carcinoma with squamous metaplasia.
\end{abstract}

Conclusion: Renal cell carcinoma can present in unusual ways. Sometimes, it can mimic emphysematous pyelonephritis because of fistulous communication with gut. It is rare but challenging for urologists to diagnose and manage such cases.

Keywords: Renal cell carcinoma, Renocolic fistula, Non-functioning kidney, Emphysematous pyelonephritis, Case report

\section{Background}

Renal malignancies associated with inflammatory diseases, such as renal abscess and pyelonephritis, can lead to a delay in the detection of the disease. Moreover, imaging studies sometimes cannot distinguish between these two diseases [1]. Discriminating between benign conditions and malignancies may be difficult in nonfunctioning kidneys unless nephrectomy is performed, as reported in the literature [2]. Furthermore, the number of studies and case reports reporting tumors in specimens from patients undergoing nephrectomy for emphysematous pyelonephritis is limited.

\footnotetext{
*Correspondence: Manhar.urologist2020@gmail.com
}

Dispur Hospital, Guwahati, India

\section{Case presentation}

A 56-year-old male patient presented with pain in the left flank, off and on for 1 year. However, no fever, weight loss, cough or bowel habit changes were reported by patient. He had no significant family history or any surgical intervention in the past. On examination, mild left flank tenderness with flank bulge was present.

Urine examination revealed $15-20 \mathrm{RBC} / \mathrm{Hpf}$ and $10-12 \mathrm{WBC} / \mathrm{Hpf}$. The hemoglobin was $8.0 \mathrm{gm} / \mathrm{dl}$, total count 17,800 , blood urea $30 \mathrm{mg} / \mathrm{dL}$, and serum creatinine $0.8 \mathrm{mg} / \mathrm{dL}$. X-ray of the kidney, ureter and bladder (KUB) showed the presence of left renal calculi with multiple air foci within renal parenchyma. Ultrasound evaluation showed left renal calculi $(18 \mathrm{~mm})$ with intrarenal air collection and left perirenal collection $(30 \times 19 \mathrm{~mm})$. CT urography was done which revealed multiple left renal 


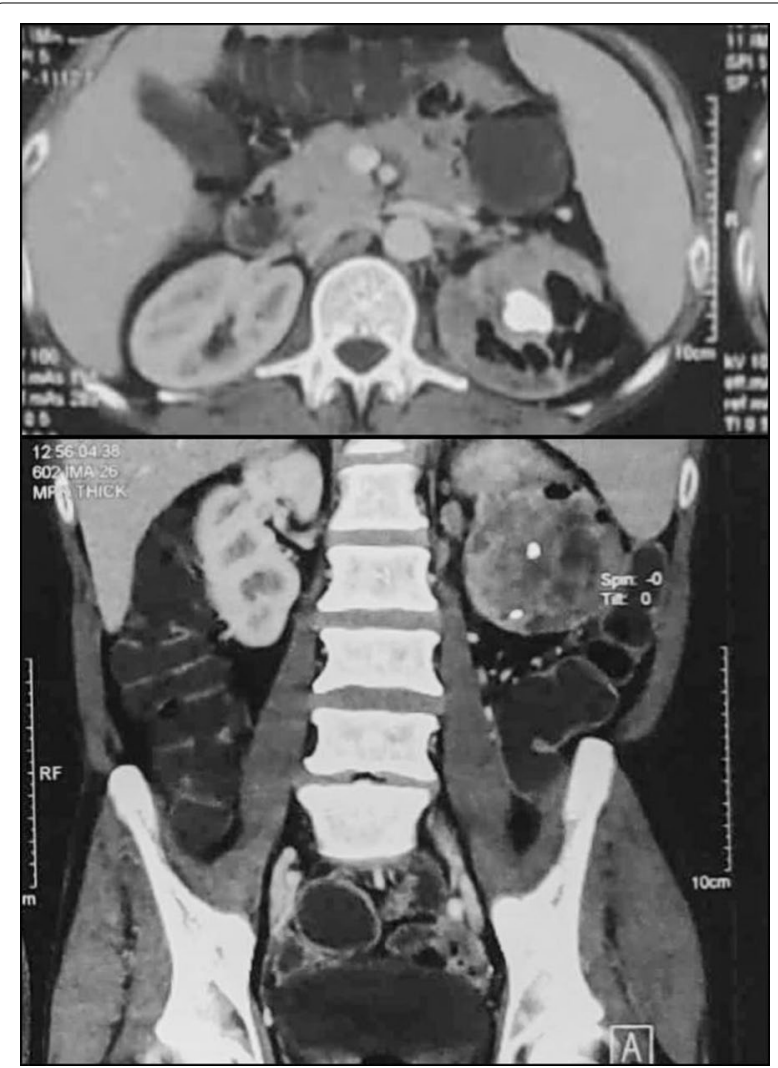

Figure 1 CT urography

which showed eGFR of $10.49 \mathrm{ml} / \mathrm{min}$ (13.75\%) on left and $76.21 \mathrm{ml} / \mathrm{min}$ on right kidney. The patient was taken up for left nephrectomy. Eleventh rib lank incision was given initially. Later on, the upper pole of the kidney was found to be adhered to the diaphragm; therefore, the incision was converted to thoracoabdominal incision.

Intraoperative findings include dense perinephric adhesions involving descending colon and psoas major muscle. On further dissection, renocolic fistula was identified. Few left para-aortic lymph nodes were present. The entire kidney was necrotic, so it was removed piecemeal. As the obstructing stone could not be identified in kidney specimen, fluoroscopy was done. The stone was found to be present in the pelvis. Stone was palpated in sigmoid colon which was removed through fistulous tract (Figs. 2, 3). Biopsy was taken from the fistulous tract, and resection anastomosis of descending colon segment with loop ileostomy was done.

Histopathological examination showed a poorly differentiated high-grade clear cell carcinoma with squamous metaplasia, Ureteric margins were free of tumor. Lymph node examination revealed reactive lymphadenitis. Biopsy from fistulous tract was positive for malignancy. The patient developed septicaemia on POD 2 which was managed by ICU support. On follow-up, his general health condition deteriorated. He was hospitalized again after 2 months. However, he could not survive despite our best efforts.

calculi and emphysematous pyelonephritis with distortion of renal architecture without demonstrable contrast excretion (Fig. 1).

Initially, patient was managed conservatively. Retrograde pyelography did not reveal fistulous tract. However, left-sided DJ stent was inserted. Patient improved with these measures. After 6 weeks, DTPA scan was done

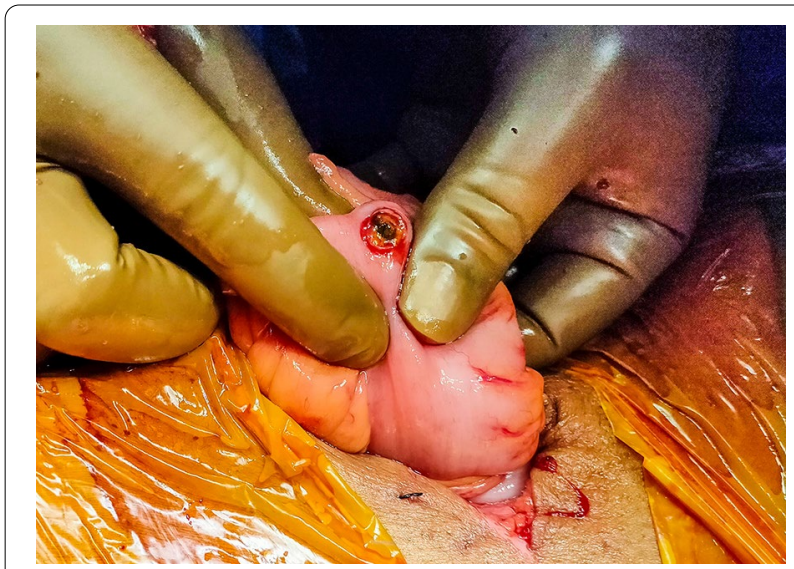

Figure 2 Renocolic fistula with stone

\section{Discussion}

A renocolic fistula, although infrequent, most often results from an acute or chronic process in the kidney. Because of the proximity of the ascending and descending portions of the colon to the kidneys, these areas are most often affected, but the sigmoid colon and cecum sometimes have been involved [3].

Fistulous tract formation can occur in any region affected by ischemia, chronic inflammation or necrosis. Although first described by Hippocrates, a fistula between renal pelvis and colon is a rare entity. Renocolic fistula usually results from penetrating trauma and less commonly from diverticular disease, colonic malignancy or inflammatory bowel disease [3, 4]. Renocolic fistula presenting as emphysematous pyelonephritis is extremely rare. There are very few reported cases in the literature. A case of spontaneous renocolic fistula associated with $\mathrm{RCC}$ was reported by Blatstein LM et al. It was successfully managed by left radical nephrectomy with descending colon resection [4]. Another case of RCC with gastro-renal fistula was reported by Tam $\mathrm{E}$ et al. Here, the gastro (stomach)-renal fistula was likely a result of necrosis caused by progressive tumor growth. In both the cases, renal mass was detected in contrast CT 


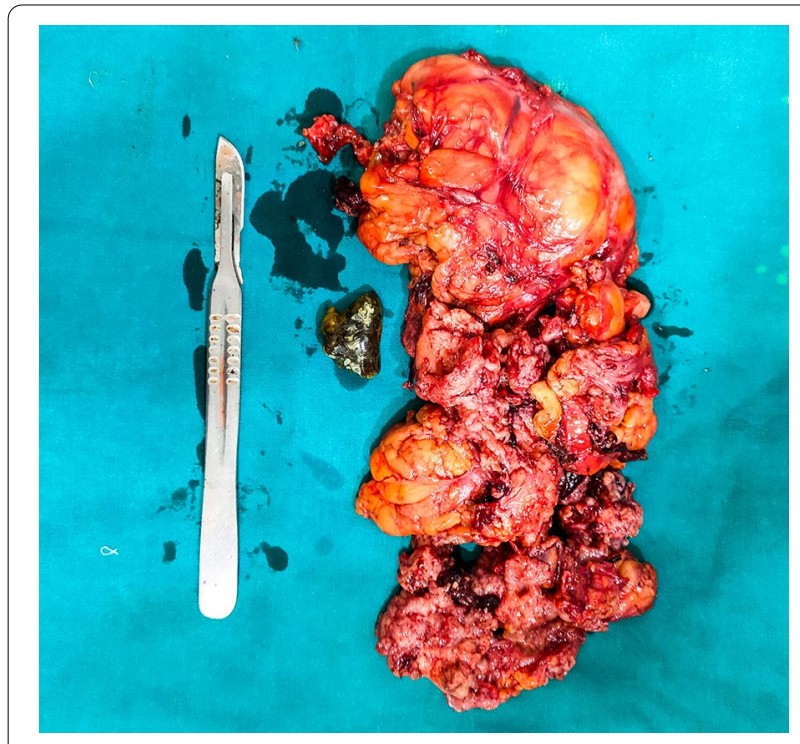

Figure 3 Kidney specimen

abdomen [5]. In contrary to reported cases in the literature, our case was diagnosed retrospectively. Multiple air foci in left kidney, seen in NCCT KUB, were secondary to fistulous communication with descending colon.

The majority of patients have non-specific symptoms, including malaise, non-specific GI symptoms, urinary frequency, flank mass or tenderness. Approximately $60-70 \%$ of patients have flank pain, fever and pyuria. Gastrointestinal examinations, such as barium enema examinations, are rarely diagnostic [6]. In a non-functioning kidney, CT urography may fail to delineate fistula. Retrograde ureteropyelography is the standard of reference for making the definitive diagnosis [7]. In our case, the gas in the kidney can be explained retrospectively by the presence of fistula with colon.

The treatment includes nephrectomy, excision and closure of the fistula or bowel resection with primary anastomosis. If renal preservation is necessary (e.g., solitary kidney), diverting colostomy should be performed along with closure of the fistula.

\section{Conclusion}

Renal cell carcinoma can present in unusual ways. Sometimes, it can mimic emphysematous pyelonephritis because of fistulous communication with gut. It is rare but challenging for urologists to diagnose and manage such cases.

\section{Abbreviations}

CT: Computed tomography; NCCT: Non-contrast computed tomography; Gl: Gastrointestinal; POD: Postoperative day.

\section{Authors' contribution}

PMD, SS and MR performed the surgery. MR collected data and has written the manuscript. All authors have read and approved the manuscript.

\section{Declarations}

\section{Consent for publication}

Written consent forpublication was obtained from the patient.

\section{Competing interests}

The authors declare that they have no competing interests.

Received: 29 March 2021 Accepted: 12 June 2021

Published online: 30 June 2021

\section{References}

1. Tsai TH, Tang SH, Chuang FP, Wu ST, Sun GH, Yu DS, Chang SY, Cha TL (2009) Ipsilateral synchronous neoplasms of kidney presenting as acute pyelonephritis and bladder metastasis. Urology 73(1163):e9-1163.e11

2. Khalid S, Zaheer S, Zaheer S, Ahmad I, Khalid M (2013) Xanthogranulomatous pyelonephritis: rare presentation of a rare disease. South Asian J Cancer

3. Arthur GW, Morris DG (1966) Reno-alimentary fistulae. Br J Surg 53:396-402

4. Blatstein LM, Ginsberg PC (1996) Spontaneous renocolic fistula: a rare occurrence associated with renal cell carcinoma. J Am Osteopath Assoc 96(1):57-59

5. Tam E, Neculiseanu E, Sidhu G (2020) Refractory Renal cell cancer with gastro-renal fistula: a rare complication. Cureus 12(1)

6. Desmond JM, Evans SE, Couch A et al (1989) Pyeloduodenal fistulae: a report of two cases and review of the literature. Clin Radiol 40(3):267-270

7. Lang EK, Fritzche P (1990) Fistulas of the genitourinary tract-clinical urography: an atlas and textbook of urologic imaging, Saunders, Philadelphia, pp 2579-83

\section{Publisher's Note}

Springer Nature remains neutral with regard to jurisdictional claims in published maps and institutional affiliations. 